\title{
ON THE EXISTENCE OF LINEAR AND BILINEAR MULTIPLIERS ON LORENTZ SPACES
}

\author{
ENJI SATO
}

Abstract. First we show that any translation invariant bounded linear operator from $L^{p, t}(\mathbf{R})$ the Lorentz space on $\mathbf{R}$ to $L^{p, s}(\mathbf{R})(1<p<\infty, 1 \leqslant s<t<\infty)$ is trivial, whose result improves Blozinski's result [4]. Next let $\phi$ be a bounded continuous function on $\mathbf{R}^{2}$, and

$$
T_{\phi}(f, g)(x)=\iint \phi(\xi, \eta) \hat{f}(\xi) \hat{g}(\eta) e^{i x(\xi+\eta)} d \xi d \eta
$$

the bilinear operator on Lorentz spaces. Then, we prove that the bounded bilinear operator $T_{\phi}$ is trivial in some cases of Lorentz spaces.

Mathematics subject classification (2010): Primary 43A22; secondary 42A45.

Keywords and phrases: Lorentz spaces, bilinear operator.

\section{REFERENCES}

[1] N. H. Asmar, E. Berkson And J. Bourgain, Restrictions from $\mathbf{R}^{n}$ to $\mathbf{Z}^{n}$ of weak type $(1,1)$ multipliers, Studia Math., 108 (1994), 291-299.

[2] O. BLASCO, Notes on the spaces of bilinear multipliers, Advanced courses of mathematical analysis III, 28-38, World Sci. Publ.,Hackensack, NJ, 2008.

[3] O. BlasCO AND F. VILlarRoYA, Transference of bilinear multilinear operators on Lorentz spaces, IIlinois J. Math., 47 (2003), 1327-1343.

[4] A. P. Blozins Ki, Convolution of L $(p, q)$ functions, Proc. Amer. Math. Soc., 32 (1972), 237-240.

[5] D. FAn And S. SATo, Transference on certain multilinear operators, J. Aust. Math. Soc., 70 (2001), 37-55.

[6] L. Grafakos And R. H. TORRES, Multilinear Calderon-Zygmund Theory, Advances in Math., 165 (2002), 124-164.

[7] K. E. Hare And E. SATo, Spaces of Lorentz multipliers, Canad. J. Math., 53 (2001), 565-591.

[8] L. HÖMANDER, Estimates for translation invariant operators in $L^{p}$ spaces, Acta Math., 104 (1960), 93-140.

[9] R. Hunt, On L(p,q) spaces, Enseign. Math., 12 (1966), 249-276.

[10] M. KANEKO AND E. SATO, Notes on transference of continuity from maximal Fourier multiplier operators on $\mathbf{R}^{n}$ to those on $\mathbf{T}^{n}$, Interdiscip. Inform. Sci., 4 (1998), 97-107.

[11] M. LACEY AND C. ThiEle, $L^{p}$ estimates on the bilinear Hilbert transform, Ann. of Math., 146 (1997), 693-724.

[12] R. LARSEN, An introduction to the thory of multipliers, Springer-Verlag, Berlin-Heidelberg-New York, 1971.

[13] J. RAPOSO, Weak type (1,1) multipliers on LCA groups, Studia Math., 122 (1997), 123-130.

[14] F. Villarroya, Bilinear multipliers on Lorentz spaces, Czechoslovak Math. J., 58, 4 (2008), 10451057.

[15] K. Wozniakowski, A new proof of the restriction theorem for weak type $(1,1)$ multipliers on $\mathbf{R}^{n}$, Illinois J. Math., 40 (1996), 479-483. 